\title{
Evaluation of applying statistical process control techniques to daily average feeding behaviors to detect disease in automatically fed group-housed preweaned dairy calves
}

\author{
W. A. Knauer, ${ }^{* 1}$ S. M. Godden, ${ }^{*}$ A. Dietrich, $†$ D. M. Hawkins, $\ddagger$ and R. E. James $\S$ \\ ${ }^{*}$ Department of Veterinary Population Medicine, University of Minnesota, St. Paul 55108 \\ †Cargill Animal Nutrition, Minneapolis, MN 55440 \\ ‡Professor Emeritus, Department of Statistics, University of Minnesota, Minneapolis 55445 \\ §Professor Emeritus, Department of Dairy Science, The Virginia Polytechnic and State University, Blacksburg 24061
}

\section{ABSTRACT}

Group housing and computerized feeding of preweaned dairy calves are gaining in popularity among dairy producers, yet disease detection remains a challenge for this management system. The aim of this study was to investigate the application of statistical process control charting techniques to daily average feeding behavior to predict and detect illness and to describe the diagnostic test characteristics of using this technique to find a sick calf compared with detection by calf personnel. This prospective cross-sectional study was conducted on 10 farms in Minnesota ( $\mathrm{n}=$ $4)$ and Virginia $(\mathrm{n}=6)$ utilizing group housing and computerized feeding from February until October 2014. Calves were enrolled upon entrance to the group pen. Calf personnel recorded morbidity and mortality events. Farms were visited either every week (MN) or every other week (VA) to collect calf enrollment data, computer-derived feeding behavior data, and calf personnel-recorded calf morbidity and mortality. Standardized self-starting cumulative sum (CUSUM) charts were generated for each calf for each daily average feeding behavior, including drinking speed $(\mathrm{mL} / \mathrm{min})$, milk consumption (L/d), and visits to the feeder without a milk meal (no.). A testing subset of 352 calves (176 treated, 176 healthy) was first used to find CUSUM chart parameters that provided the highest diagnostic test sensitivity and best signal timing, which were then applied to all calves $(\mathrm{n}=1,052)$. Generalized estimating equations were used to estimate the diagnostic test characteristics of a single negative mean CUSUM chart signal to detect a sick calf for a single feeding behavior. Combinations of feeding behavior signals were also explored. Single signals and combinations of signals that

\footnotetext{
Received October 5, 2017.

Accepted May 21, 2018.

${ }^{1}$ Corresponding author: knaue020@umn.edu
}

included drinking speed provided the most sensitive and timely signal, finding a sick calf up to an average $( \pm \mathrm{SE})$ of $3.1 \pm 8.8 \mathrm{~d}$ before calf personnel. However, there was no clear advantage to using CUSUM charting over calf observation for any one feeding behavior or combination of feeding behaviors when predictive values were considered. The results of this study suggest that, for the feeding behaviors monitored, the use of CUSUM control charts does not provide sufficient sensitivity or predictive values to detect a sick calf in a timely manner compared with calf personnel. This approach to examining daily average feeding behaviors cannot take the place of careful daily observation.

Key words: group housing, feeding behavior, calf health, statistical process control

\section{INTRODUCTION}

Group housing and computerized feeding of dairy calves during the preweaning period are gaining in popularity among dairy producers worldwide, with an estimated $15 \%$ of preweaned dairy calves in the United States housed in groups (USDA-NAHMS, 2016). Computerized milk feeding systems offer an easy method to deliver more milk (Huuskonen and Khalili, 2008; Roth et al., 2008), reductions in labor needed per calf (Kung et al., 1997), and social benefits for the calf (Jensen et al., 1999; De Paula Vieira et al., 2012). However, morbidity (Svensson et al., 2003) and mortality risks (Losinger and Heinrichs, 1997) are significantly increased in large groups ( $\geq 7$ calves) compared with small groups. Additionally, timely disease detection can be a challenge for calves housed in groups (Steenkamer, 1982; Cramer et al., 2016). Therefore, management tools and strategies that can help dairy producers predict and detect disease are of great interest for producers who use this calf rearing strategy.

One potential solution to the challenge of disease detection is that computer software can record and report 
individual calf feeding behaviors that may be associated with illness. For example, the Kalb Manager feeding software program (Förster-Technik, Engen, Germany) provides the producer with an alert when an individual calf deviates in its 3-d average drinking speed or milk consumption by 25\% (Jan Zimerick, Förster-Technik North America, Cambridge, ON, Canada; personal communication). However, the accuracy and timeliness of current algorithms to detect disease are unknown. For example, in one observational study Borderas et al. (2009) found that calves fed a high level of milk (>8 L/d) decreased their daily average milk intake (consumption, CON; L/d) on the same day that they were detected as sick by a trained human observer. Furthermore, in the same study, calves offered a restricted level of milk $(4 \mathrm{~L} / \mathrm{d})$ did not reduce their daily average milk intake at all during a period of illness. In another study, Svensson and Jensen (2007) reported that sick calves had a reduction in the number of visits to the feeder without a milk meal (unrewarded visits, URV; visits/d), but there was no difference between sick and healthy calves in the speed of milk CON (drinking speed, DS; $\mathrm{mL} / \mathrm{min})$ or rewarded visits (RV; visits/d) to the feeder. These studies suggest that current computer feeder software algorithms that use daily averages may have limited utility as an indicator of disease onset in that they lack in sensitivity compared with a trained human observer. However, a different approach to evaluate changes in feeding behavior in individual animals could result in a more sensitive and timely monitoring technique to detect morbidity in group-housed calves, which could result in prompt treatment and improved calf performance.

Statistical process control (SPC) is an analytical approach traditionally used in manufacturing process monitoring that uses control charts to differentiate common cause from special cause variation in a process over time (Hawkins and Olwell, 1998). Common cause variation represents the normal variation in any system over time. For example, the average calf may drink at a speed of $1,000 \mathrm{~mL} / \mathrm{min}$ overall, but she may vary from 800 to $1,200 \mathrm{~mL} / \mathrm{min}$ depending on unexplained environmental and individual calf factors. If her DS suddenly decreased to $200 \mathrm{~mL} / \mathrm{min}$, this could represent special cause variation, which can be the result of a health event, human error, or technical failure (Mertens et al., 2011). With the advent of precision livestock farming and the abundance of sensor-derived information, efforts have been made in the past decade to apply these analytical techniques to production data to monitor health (De Vries and Reneau, 2010). For example, by applying self-starting cumulative sum (CUSUM) control charts to steer feeding time, Quimby et al. (2001) reported that they could detect a sick feeder calf up to $4.5 \mathrm{~d}$ earlier than an experienced pen rider. Madsen and Kristensen (2005) applied similar methodologies to pen-level water intake in piglets and found that they could predict a diarrheal outbreak $1 \mathrm{~d}$ before clinical signs were observed. There can be value in finding these animals early in the disease process through the potential reduction of progression of disease by prompt intervention.

Traditionally, control charting has been used in manufacturing where historical data were available and common cause variation was minimal. However, certain challenges are introduced when we consider applying this approach to biological systems. For example, when a calf enters a group pen, we have no historical data on its behavior yet want to begin monitoring as soon as possible because disease can occur early in the feeding period. Self-starting cumulative sum control charts may be useful to address this problem (Hawkins and Olwell, 1998). In this procedure, the first several observations are used to establish the process mean and variance, and then both are updated with each new observation. These charts also have an advantage over other charting methods in that they are sensitive to small shifts, which are particularly of interest in biological processes (Mertens et al., 2011). The sensitivity of the chart to signal is determined by the upper and lower control limits, defined as the multiples of the SD by which the calculated CUSUM statistic is allowed to vary. When this value falls outside the upper or lower limits as predetermined by the user, the process is then investigated.

The objective of this study was to evaluate the sensitivity and timeliness of applying CUSUM charting techniques to computer feeder sensor-derived daily averages of dairy calf feeding behaviors to find a sick calf compared with trained calf personnel. We hypothesized that the application of CUSUM charting techniques to daily average individual calf feeding behavior data, alone or in combination, would be useful to detect a sick calf in a timely and sensitive manner compared with trained calf personnel. If successful, we anticipated that this technique could be applied to calf feeding behaviors in computer feeder software algorithms as a screening test to aid producers in the detection of sick calves in the field.

\section{MATERIALS AND METHODS}

The use of animals in the study was approved by the University of Minnesota Institutional Animal Care and Use Committee (protocol no. 1308-30844A). This manuscript was prepared according to the Standards for Reporting of Diagnostic Accuracy Studies (Bossuyt et al., 2015). 


\section{Farm Selection}

This prospective cross-sectional study was conducted in a convenience sample of 10 commercial dairy farms (4 in Minnesota and 6 in Virginia) ranging in size from 110 to 850 lactating cows; 1 farm was a custom heifer grower. Farms were selected based on their use of an automated calf feeding system (Förster-Technik) that must have been in use for more than 1 yr duration. Four farms had 2 feeders with 4 pens of calves, and 6 farms had 1 feeder and 2 pens of calves, with each pen having 1 nipple feeding station. Average full feeding level offered was $9.4 \mathrm{~L} / \mathrm{d}$ (range: 7-16) fed at a TS concentration of $155 \mathrm{~g} / \mathrm{L}$ (range: 143-165). All farms managed calves in individual housing before introduction; average $( \pm \mathrm{SD})$ age at introduction to the group pen was $9 \pm 5 \mathrm{~d}$, with a group size of $17 \pm 5$ calves per group. Calves were weaned from milk at $55 \pm 8 \mathrm{~d}$ of age.

\section{Calf Management and Data Collection}

Data collection occurred from February 2014 to October 2014 on all farms. An initial questionnaire was used to describe calf facilities and general calf management. Heifer and bull calves were enrolled in the study when they entered the group pen and exited the study when they were weaned from the automatic feeder. For each calf entering a group pen, calf personnel recorded the calf ID, breed, sex, birth date, and pen entry date. Sick calves were identified based on daily subjective evaluations by the calf personnel, and the date, time, treatment, and disease treated were recorded for each morbidity event. Mortality events were recorded similarly. Case definitions were standardized across farms through training and use of a visual scoring system that evaluates ocular and nasal discharge, cough, head tilt, fecal score, and general attitude (McGuirk, 2008).

A study technician visited the farm each week (MN) or biweekly (VA) to collect calf enrollment data, treatment records, and mortality data. Day-level average feeding behavior data were collected through the automatic feeding software program (Kalb Manager, Förster-Technik) at each farm visit by the study technician. Specific daily average feeding behaviors recorded included daily average CON, DS, URV, and RV. Calf personnel were blinded to sensor-derived feeding behavior data throughout the study beyond what was already being reported and used for animal monitoring by the on-farm software. The Kalb Manager software provides DS, CON, and deviation data to the user. Calf personnel on 6 of the 10 study farms used CON to screen calves, but none used the data for the sole purpose of calf diagnosis or treatment.

\section{Statistical Analysis}

Sample Size. A total of 1,052 calves were enrolled on 10 farms in Minnesota and Virginia. Sixty-three percent of calves had a first treatment, resulting in 660 treated calves and 392 healthy calves. This sample size ( $>250$ calves per group) provided in excess of $80 \%$ power and $95 \%$ confidence to detect a 1 - $\mathrm{L}$ difference in daily milk intake (i.e., 8 vs. $7 \mathrm{~L} / \mathrm{d}$ ) between sick and healthy calves [assumed an SD $(k)=0.5 \mathrm{~L} / \mathrm{d}$; 1 -tailed test].

Treatment Definitions. Diarrhea (50\%; 331/660) was defined as visible diarrhea (very loose or watery feces; fecal score of 2 or 3 on a $0-3$ scale) as well as treatment with antibiotics, electrolytes, intravenous fluids, or a combination of the 3. Respiratory (19\%; $127 / 660$ ) disease was defined as a calf with an increased respiratory rate or effort, cough, and treatment with antibiotics. Ill-thrift $(30.6 \% ; 202 / 660)$ was defined as (1) a calf that had a rectal temperature $>39.5^{\circ} \mathrm{C}$; (2) a calf that was depressed but for which calf personnel did not have a clear diagnosis or; (3) a calf with other miscellaneous illnesses such as umbilical infection, joint infection, or injury and treatment with antibiotics or nonsteroidal anti-inflammatories. Treatments known to be prophylactic (i.e., antibiotic administered to all calves at pen entry) occurred on 1 farm and were excluded from analysis. Although some calves were treated multiple times for multiple diseases, only the first treatment event was considered for the analysis. First treatments occurred at an average \pm standard deviation of $9.3 \pm 8.5 \mathrm{~d}$ after introduction to the group pen, and calves diagnosed with illness were treated an average duration of $3.8 \pm 3.9 \mathrm{~d}$.

Investigation of CUSUM Model Parameters. A matched pair analysis was first performed to determine the difference in feeding behaviors in a matched pair of sick and healthy calves ( $\mathrm{n}=176$ pairs) around the time of treatment for clinical disease, which is described elsewhere (Knauer et al., 2017). The results of that analysis showed that reductions in daily average DS, CON, and URV were all significantly associated with treatment for clinical disease both before and during treatment and were subsequently investigated as potential feeding behaviors of interest for analysis. Prior to the application of CUSUM control charts to the data, daily average feeding behaviors (DS, CON, URV) were graphed and assessed for normality, and then several data preprocessing steps were taken.

The CON and URV feeding behavior data had many " $0 \mathrm{~s}$ " or repetitive numbers (i.e., $\mathrm{d} 1=5 \mathrm{~L}, \mathrm{~d} 2=5 \mathrm{~L}$ ) at the beginning of the feeding period. To ensure sufficient variation for CUSUM functioning, a random number between 0 and 0.01 was added to all of the $\mathrm{CON}$ and 
URV daily average measurements for all calves. This processing step provided enough variation so that the CUSUM charts would run without providing too much variation and causing false-positive signals. Feeding behavior data are nonstationary; individual calf DS and URV increased over the time the calf was in the group pen (DS increased by $11 \mathrm{~mL} / \mathrm{min}$ per feeding day; URV increased by 0.17 URV per feeding day), and CON followed a curve similar to the feeding plan of the calf, increasing in the first days in the pen, holding at a maximum feeding level, and then decreasing as the calf was weaned from milk (Knauer et al., 2017). These data characteristics can lead to both false-positive and falsenegative CUSUM signals. Therefore, as an additional data processing step, feeding behaviors were standardized to the average calf for each day of the feeding period. This was done by dividing each individual calf's feeding behavior by the average calf feeding behavior (i.e., average of all 1,052 calves) for each feeding day. In this way, if a calf represented the average calf for the entire feeding period, the feeding behavior for each day would be 1. Standardized self-starting CUSUM charts were then generated for DS, CON, and URV for a training set of calves $(\mathrm{n}=352)$ for the entire milk feeding phase as described by Hawkins and Olwell (1998) using R Statistical Software (version 3.3.0; R Core Team, Vienna, Austria).

The training data set $(\mathrm{n}=352)$ was used to identify the CUSUM chart parameters that provided the highest sensitivity of detection for each feeding behavior. Terms relating to the CUSUM charts are briefly explained below. The self-starting methodology is described in detail in Hawkins and Olwell (1998). It takes a stream of normally distributed values $X_{n}$ with unknown true mean and standard deviation and transforms them to a stream of values $U_{n}$ that are normally distributed with mean 0 and standard deviation 1 . Based on our work and the work of others (Borderas et al., 2009; Knauer et al., 2017) that showed an association between clinical diagnosis of illness and reductions in DS, CON, and URV, the downward (S-) CUSUM for the self-starting mean was chosen as the test of interest and was calculated using the following equation (Hawkins and Olwell, 1998):

$$
S_{n}^{-}=\max \left(0, S_{n-1}^{-}-U_{n}+k\right),
$$

where

$$
U_{n}=\text { inverse normal }\left[\left(F_{n-2} \sqrt{\frac{n-1}{n}}\right)\left(\frac{X_{n}-\bar{X}_{n-1}}{S_{n-1}}\right)\right] \text {, }
$$

$k$ is one-half the shift in mean that the CUSUM is optimized to detect, and $F_{n-2}$ is the cumulative distribution function of the Student's $t$ distribution with $n-2$ degrees of freedom. Further details can be obtained from software provided by Hawkins and Olwell (1998; http://www.stat.umn.edu/cusum/software.htm).

The reference value $k$ was held constant for all charting $(k=0.5)$, which corresponds to a step change of $1 \mathrm{SD}$ of the feeding behavior evaluated. To determine when the mean had shifted from the self-starting mean, upper and lower control limits were specified. The upper and lower control limits were varied to investigate the effects of changing the control limits on the sensitivity and timing of the chart to signal. The narrower the limits, the fewer observations the CUSUM requires for a false-positive signal when applied to normally and independently distributed data. See Table 1 for falsepositive rates relative to control limit. Limits investigated included \pm 3.5 to \pm 1.5 in 0.5 -unit increments. Only the first signal to occur in the feeding period was used in this analysis regardless of when the signal occurred.

Diagnostic test characteristics for a signal to detect a sick calf compared with detection by calf personnel were calculated for each of the feeding behaviors at each of the control limits ( \pm 3.5 to \pm 1.5 in 0.5 -unit increments) from $2 \times 2$ tables. Signal represented the index test and populated the left side of the table with positive (days with signal) and negative (days without signal) tests, and clinical diagnosis and treatment by calf personnel represented the reference test (gold standard) and populated the top of the table with treated calves (calves with treatment for clinical disease) and healthy calves (calves without treatment for clinical disease) represented. Diagnostic test characteristics included sensitivity (Se), specificity (Sp), accuracy, and the false-positive rate. Sensitivity was defined as the proportion of truly sick calves (as identified by calf personnel) that had a positive signal. Specificity was defined as the proportion of healthy calves (never diagnosed by calf personnel as sick) that never had a signal. Accuracy was defined as the total proportion of days with a signal or days without a signal that correctly identified a sick or healthy calf. The false-positive rate was defined as the proportion of signals that incorrectly identified a calf as sick (Dohoo et al., 2009).

The diagnostic test characteristics for each detection limit for each feeding behavior were determined. For those calves that achieved a signal and were truly sick (true positives), the timeliness of the signal was assessed based on subtracting the date of the signal from the date that calf personnel identified the calf as sick. 
After completing this analysis for all combined clinical disease treatments, this analysis was repeated for each individual disease diagnosed (respiratory, ill-thrift, or diarrhea). However, the goal of this test was to find a sick calf in a pen of calves, so the individual disease results are not reported.

CUSUM Diagnostic Test Characteristics. After completing the previously described analysis using the training data set ( $\mathrm{n}=352$ calves), the data form and control limits (upper and lower) with the highest diagnostic test Se were determined (Table 1). We expected that the narrowest control limits would provide more signals and therefore a higher Se to detect a sick calf. Drinking speed had the highest Se when raw DS was charted at a control limit of \pm 1.5 . Daily average milk CON had the highest Se when standardized CON was charted at a control limit of \pm 1.5 , and URV had the highest Se when standardized URV was charted at a control limit of \pm 1.5 . Standardized self-starting CUSUM charts were then created for each calf in the data set $[\mathrm{n}=1,052$ for each feeding behavior (CON, DS, URV)] using R (version 3.3.0; R Core Team).

Descriptive statistics calculated included timing of signal relative to day on the automatic feeder and, for treated calves, the timing of the signal relative to the first day of treatment. A mixed model was used to estimate timing of the signal relative to days on the feeder and days from treatment for each single and combination of feeding behaviors. Farm was controlled for as a random effect, and a Bonferroni correction was used to account for multiple comparisons. Diagnostic test characteristics [Se, Sp, accuracy, positive predictive value (PPV), and negative predictive value (NPV)] of using a single signal to detect a sick calf were estimated using generalized estimating equations, accounting for the random effect of farm. The PPV was defined as the proportion of signals that correctly identified a sick calf, and NPV was defined as the proportion of days without signals that correctly identified a healthy calf (Dohoo et al., 2009). First, univariable models were generated to describe the relationship between a signal (yes/no) and predictors of interest including calf treatment (yes/ no; main predictor of interest), breed, age at pen exit, age at signal, feeding day (day in the group pen; no.), sick before entrance to the feeder (yes/no), pen, and region. Variables that were significant $(P<0.20)$ in a univariable model were then offered to the full model, and backward stepwise elimination was used until all variables remaining were significant at $P<0.05$.

Sensitivity and Sp were predicted when a signal was the outcome and calf treatment was the main predictor of interest. To estimate predictive values, the outcome variable was calf treatment with the main predictor being a day with a signal. Final models (Se/Sp and

Table 1. Diagnostic test characteristics ${ }^{1}$ and signal timing ${ }^{2}$ for the first self-starting cumulative sum (CUSUM) signal on a negative mean feeding behavior ${ }^{3}$ to detect a sick calf calculated from $2 \times 2$ tables in a testing subset of calves $(\mathrm{n}=342)$ at different decision intervals ${ }^{4}$

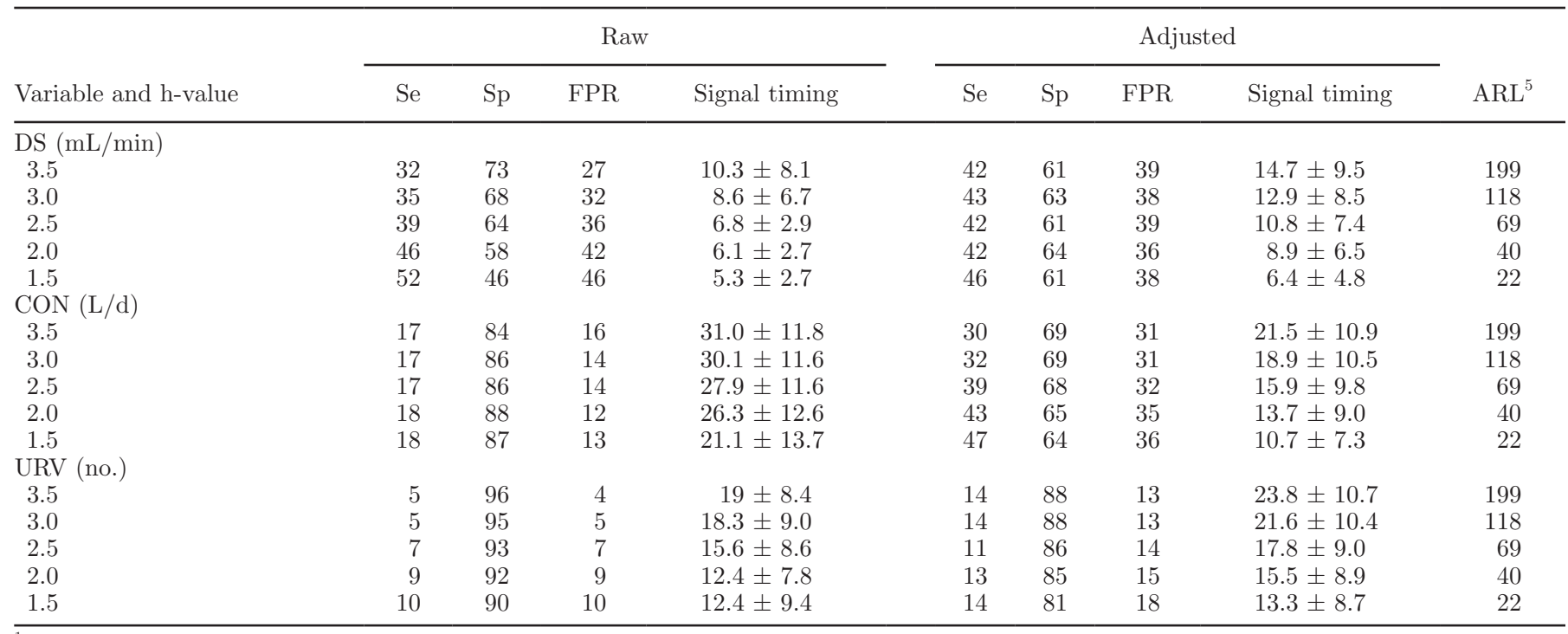

${ }^{1} \mathrm{Se}=$ sensitivity; $\mathrm{Sp}=$ specificity; FPR $=$ false positive rate.

${ }^{2}$ Calf days on the feeder at the time of a first CUSUM signal (mean $\pm \mathrm{SD}$ ).

${ }^{3} \mathrm{DS}=$ daily average drinking speed; CON $=$ daily average milk consumption; URV $=$ daily average unrewarded visits to the feeder. Raw $=$ data as collected from the automatic feeder; adjusted = feeding behavior standardized to the average calf by day on feeder.

${ }^{4} \mathrm{~h}$-value.

${ }^{5}$ Average run length $=$ average number of observations in a CUSUM run before a false-positive signal when applied to normally and independently distributed data. 
$\mathrm{PPV} / \mathrm{NPV}$ ) for all feeding behaviors included the main outcome and predictor only and controlled for the random effect of farm. Test characteristics and 95\% confidence intervals were calculated from model output as described by Dohoo et al. (2009). Finally, the utility of using feeding behaviors in combination was investigated. For the latter, the diagnostic test characteristics of using 2- and 3-way combinations of DS, CON, and URV were modeled similarly using both parallel and series interpretation. With series interpretation, only calves that have signals to both feeding behaviors are considered test positive. With parallel interpretation, animals that have signals to one feeding behavior, the other feeding behavior, or both feeding behaviors are considered test positive (Dohoo et al., 2009). All statistical modeling was performed in SAS (version 9.4; SAS Institute Inc., Cary, NC).

\section{RESULTS}

\section{Feeding Behaviors for the CUSUM Stream}

The average (SD) DS data that were fed into the CUSUM for all calf days $(\mathrm{n}=43,607)$ for all calves $(\mathrm{n}=1,052)$ was $877(344) \mathrm{mL} / \mathrm{min}$. The average (SD) CON and URV were $6.6(2.3) \mathrm{L} / \mathrm{d}$ and 7.2 (7.7) visits, respectively. The feeding behaviors of the training data set of calves that were fed into their respective CUSUM can be found in Table 2. Further information on the feeding behaviors for calves in this study is reported in Knauer et al. (2017).

\section{Signal Timing}

When signals on single feeding behaviors were considered, a CUSUM signal on DS occurred earliest in the feeding period $(\mathrm{n}=533 ; 5.4 \pm 2.6 \mathrm{~d})$ and was earlier than CON ( $=428 ; 10.6 \pm 6.8 \mathrm{~d} ; P<0.0001)$ or URV (n $=211 ; 10.8 \pm 7.3 \mathrm{~d} ; P<0.0001)$, which were not different from each other $(P=1)$. A single signal on DS was also earlier than any other 2- or 3-way combination
( $P \leq 0.002$ for all comparisons). Additionally, signals that occurred in 2 or 3 feeding behaviors in parallel interpretation resulted in earlier signals over all signals that occurred in 2- or 3-way series interpretation $(P \leq$ 0.002 for all comparisons; Table 3).

A single signal on DS resulted in an earlier signal compared with treatment for clinical disease $(\mathrm{n}=347$; $-2.8 \pm 8.5 \mathrm{~d})$ compared with $\mathrm{CON}(\mathrm{n}=288 ; 0.7 \pm$ $10.3 \mathrm{~d} ; P<0.0001)$ and URV $(\mathrm{n}=131 ; 1 \pm 11.3 \mathrm{~d} ; P$ $=0.005)$, which were not different from each other $(P$ $=1)$. A combined signal on DS and CON in parallel interpretation $(\mathrm{n}=463 ;-3.1 \pm 8.8)$ resulted in an earlier signal than when DS and CON were considered in parallel $(P=0.0008)$ compared with treatment for clinical disease, but the same was not true for other 2and 3-way combinations when parallel and series combinations were compared ( $P=1$ for all comparisons). Signals on DS and 2-way combinations that included DS in parallel interpretation (DS and CON, DS and URV) were earlier than all other signals or combinations of signals $(P \leq 0.043$ for all comparisons; Table 3).

The proportion of calves that signaled relative to when they were treated is reported in Table 4. For example, for a signal on DS and CON in parallel combination, $16.6 \%$ of signals occurred 8 or more days before the calf was found to be sick and $37.7 \%$ of signals occurred in the week leading up to illness detection. Fourteen percent of first $\mathrm{S}$ - signals occurred on the day the calf was found to be sick by calf personnel, and $31.5 \%$ of signals occurred after the calf was treated for illness.

\section{Diagnostic Test Characteristics}

Point estimates and $95 \%$ confidence intervals of the diagnostic test characteristics estimated from the generalized estimating equations are reported in Table 5 . When considering the ability of a signal on a single feeding behavior to detect a sick calf, a first signal on DS data had the highest Se at 56.4\% (95\% CI: 47.1, 65.5) and a PPV of $66.6 \%$ (95\% CI: 54.4, 76.9). However,

Table 2. Descriptive statistics of the feeding behaviors that were used for the self-starting cumulative sum data stream both overall $(\mathrm{n}=1,052)$ and for treated $(\mathrm{n}=176)$ and healthy $(\mathrm{n}=176)$ calves in the training data set

\begin{tabular}{|c|c|c|c|c|c|c|c|c|c|}
\hline \multirow[b]{2}{*}{ Variable $^{1}$} & & & & \multicolumn{6}{|c|}{ Training data set } \\
\hline & Mean & SD & Range & Mean & SD & Range & Mean & SD & Range \\
\hline $\mathrm{DS}(\mathrm{mL} / \mathrm{min})$ & 877 & 344 & $0-2,307$ & 858 & 340 & $0-2,234$ & 937 & 326 & $0-2,307$ \\
\hline $\mathrm{CON}(\mathrm{L} / \mathrm{d})$ & 6.6 & 2.3 & $0-16$ & 6.6 & 2.1 & $0-13$ & 6.9 & 2.2 & $0-13$ \\
\hline
\end{tabular}

${ }^{1} \mathrm{DS}=$ daily average drinking speed; CON $=$ daily average milk consumption; URV = daily average unrewarded visits to the feeder. 
Table 3. The mean \pm SD (range) timing of a signal relative to days on the calf feeder $(\mathrm{n}=1,052$ calves) and days from first treatment for treated calves $(\mathrm{n}=660 \text { calves })^{1}$

\begin{tabular}{|c|c|c|c|c|}
\hline Signal type ${ }^{2}$ & No. & Days on feeder & No. & Days from treatment \\
\hline \multicolumn{5}{|l|}{1 signal } \\
\hline DS & 533 & $5.4 \pm 2.8(3-26)^{\mathrm{a}, \mathrm{A}}$ & 347 & $-2.8 \pm 8.5(-46-16)^{\mathrm{a}, \mathrm{A}}$ \\
\hline $\mathrm{CON}$ & 428 & $10.6 \pm 6.8(3-38)^{\mathrm{b}}$ & 288 & $0.7 \pm 10.3(-40-33)^{\mathrm{b}}$ \\
\hline URV & 211 & $10.8 \pm 7.3(3-44)^{\mathrm{b}}$ & 131 & $1 \pm 11.3(-34-41)^{b}$ \\
\hline \multicolumn{5}{|l|}{2 signals } \\
\hline \multicolumn{5}{|c|}{$\mathrm{DS}$ and $\mathrm{CON}$} \\
\hline Parallel & 719 & $7.1 \pm 5.5(3-38)^{\mathrm{a}, \mathrm{B}}$ & 463 & $-3.1 \pm 8.8(-46-16)^{\mathrm{a}, \mathrm{A}}$ \\
\hline Series & 242 & $10.1 \pm 5.8(3-35)^{\mathrm{b}}$ & 172 & $0.03 \pm 9.9(-33-27)^{\mathrm{b}}$ \\
\hline \multicolumn{5}{|c|}{ DS and URV } \\
\hline Parallel & 619 & $6.9 \pm 4.2(3-42)^{\mathrm{a}, \mathrm{B}}$ & 409 & $-2.3 \pm 8.8(-46-35)^{\mathrm{AC}}$ \\
\hline Series & 128 & $10.9 \pm 6.8(4-44)^{\mathrm{b}}$ & 82 & $0.1 \pm 11.5(-35-40)$ \\
\hline \multicolumn{5}{|c|}{ CON and URV } \\
\hline Parallel & 532 & $10.2 \pm 6.8(3-42)^{\mathrm{a}, \mathrm{C}}$ & 346 & $-0.5 \pm 10.4(-41-35)^{\mathrm{BC}}$ \\
\hline Series & 107 & $13 \pm 7.4(4-44)^{\mathrm{b}}$ & 73 & $1.5 \pm 11.5(-33-40)$ \\
\hline \multicolumn{5}{|c|}{3 signals } \\
\hline \multicolumn{5}{|c|}{ DS, CON, URV } \\
\hline Parallel & 765 & $7.8 \pm 5.5(3-42)^{\mathrm{a}, \mathrm{B}}$ & 487 & $0 \pm 10.1(-46-40)^{\mathrm{B}}$ \\
\hline Series & 70 & $13.4 \pm 7.9(4-44)^{\mathrm{b}}$ & 48 & $2.1 \pm 12.9(-33-40)$ \\
\hline
\end{tabular}

${ }_{\mathrm{a}, \mathrm{b}}$ Lowercase superscripts represent significance (Bonferroni correction, $P<0.0045$ ) within the column for 1 signal and between parallel and series interpretation for 2 and 3 signals.

${ }^{\mathrm{A}-\mathrm{C}}$ Uppercase superscripts represent differences between 1 signal DS and the parallel 2- and 3-signal combinations.

${ }^{1}$ For parallel interpretation, calculations are from the date of the first signal. For series interpretation, calculations are from the date of the last signal. Significance between signal timing measures was determined using a mixed model that controlled for the random effect of farm and corrected for multiple comparisons with a Bonferroni adjustment.

${ }^{2} \mathrm{DS}=$ daily average drinking speed $(\mathrm{mL} / \mathrm{min}) ; \mathrm{CON}=$ daily average milk consumption $(\mathrm{L} / \mathrm{d}) ; \mathrm{URV}=$ daily average unrewarded visits to the feeder (no.). Parallel interpretation $=$ the signal had to be positive for DS or $\mathrm{CON}$ or both for the test to be considered positive. Series interpretation $=$ the signal had to be positive for DS and $\mathrm{CON}$ for the test to be considered positive.

Table 4. Frequency of signal (proportion of total treated calves) at different intervals before, on the day of, or after the day of treatment for all treated calves

\begin{tabular}{|c|c|c|c|c|c|c|c|}
\hline Signal type $^{1}$ & $\mathrm{No}^{2}$ & No. ${ }^{3}$ & $\begin{array}{c}\text { Signal } \geq 8 \mathrm{~d} \\
\text { before } \\
\text { treatment }\end{array}$ & $\begin{array}{c}\text { Signal } 4-7 \mathrm{~d} \\
\text { before } \\
\text { treatment }\end{array}$ & $\begin{array}{c}\text { Signal } 1-3 \mathrm{~d} \\
\text { before } \\
\text { treatment }\end{array}$ & $\begin{array}{l}\text { Signal on } \\
\text { day of } \\
\text { treatment }\end{array}$ & $\begin{array}{c}\text { Signal after } \\
\text { calf received } \\
\text { treatment }\end{array}$ \\
\hline \multicolumn{8}{|l|}{1 signal } \\
\hline $\mathrm{CON}$ & 428 & 288 & $38(13.2)$ & $24(8.3)$ & $47(16.3)$ & $43(14.9)$ & $136(47.2)$ \\
\hline URV & 211 & 131 & 19 14.5) & $9(6.9)$ & $20(15.3)$ & $17(12.9)$ & $66(50.4)$ \\
\hline \multicolumn{8}{|l|}{2 signals } \\
\hline Series & 242 & 172 & $23(13.4)$ & $9(5.2)$ & $21(12.2)$ & $28(16.3)$ & $91(52.9)$ \\
\hline \multicolumn{8}{|c|}{ DS and URV } \\
\hline Parallel & 616 & 396 & $62(15.7)$ & 44 (11.1) & $95(23.9)$ & $61(15.4)$ & $134(33.8)$ \\
\hline Series & 128 & 82 & $11(13.4)$ & $4(4.9)$ & $5(6.1)$ & $16(19.5)$ & $46(56.1)$ \\
\hline \multicolumn{8}{|c|}{ CON and URV } \\
\hline Parallel & 532 & 346 & $48(13.9)$ & $30(8.6)$ & $58(16.8)$ & 54 (15.6) & $156(45.1)$ \\
\hline Series & 107 & 73 & $9(12.3)$ & $3(4.1)$ & $9(12.3)$ & $6(8.2)$ & $46(63)$ \\
\hline
\end{tabular}

${ }^{1} \mathrm{DS}=$ daily average drinking speed $(\mathrm{mL} / \mathrm{min})$; CON = daily average milk consumption $(\mathrm{L} / \mathrm{d})$; URV = daily average unrewarded visits to the feeder (no.). Parallel interpretation = the signal had to be positive for DS or CON or both for the test to be considered positive. Series interpretation $=$ the signal had to be positive for DS and CON for the test to be considered positive.

${ }^{2}$ Total number of signal-positive calves out of total calves $(n=1,052)$.

${ }^{3}$ Total number of signal-positive calves out of total calves treated $(n=660)$. 
Table 5. Mean (95\% CI) diagnostic test characteristics ${ }^{1}$ of the ability of a signal to detect a sick calf using daily average individual animal feeding behaviors alone or in combination ${ }^{2}$

\begin{tabular}{|c|c|c|c|c|c|}
\hline Signal type ${ }^{3}$ & Sensitivity (\%) & Specificity (\%) & $\operatorname{PPV}(\%)$ & $\operatorname{NPV}(\%)$ & Accuracy (\%) \\
\hline \multicolumn{6}{|l|}{1 signal } \\
\hline DS & $56.4(47.1,65.5)$ & $49.5(41.4,57.6)$ & $66.6(54.4,76.9)$ & $38.9(29.1,47.4)$ & $53.8(49.6,57.9)$ \\
\hline \multicolumn{6}{|c|}{2 signals } \\
\hline \multicolumn{6}{|c|}{ DS and CON } \\
\hline Parallel & $70.9(62.1,78.5)$ & $32.9(26.7,40.3)$ & $65.3(53.5,75.4)$ & $38.7(28.0,50.6)$ & $57.9(52.2,63.4)$ \\
\hline Parallel & $63.6(53.2,72.8)$ & $40.7(33,1,48.7)$ & $65.7(53.7,75.9)$ & $38.4(27.9,50.2)$ & $56.2(50.4,61.8)$ \\
\hline Series & $12.7(7.3,17.5)$ & $88.5(82.4,92.7)$ & $66.5(54.0,76.9)$ & $36.3(26.1,47.8)$ & $40.2(32.1,48.8)$ \\
\hline \multicolumn{6}{|c|}{ CON and URV } \\
\hline Parallel & $51.9(45.7,58.0)$ & $51.9(44.5,59.4)$ & $65.6(53.2,76.2)$ & $37.5(27.3,48.9)$ & $52.6(49.3,55.9)$ \\
\hline Series & $10.5(7.8,14.1)$ & $91.8(87.3,94.8)$ & $69.8(60.7,77.5)$ & $36.5(25.8,48.6)$ & $39.9(30.0,50.9)$ \\
\hline \multicolumn{6}{|c|}{3 signals } \\
\hline \multicolumn{6}{|c|}{ DS, CON, URV } \\
\hline
\end{tabular}

${ }^{1} \mathrm{PPV}=$ positive predictive value; NPV $=$ negative predictive value. Both were calculated in a population with a first-treatment prevalence of $63 \%$.

${ }^{2}$ Point estimates are the result of generalized estimating equations controlling for the random effect of farm.

${ }^{3} \mathrm{DS}=$ daily average drinking speed $(\mathrm{mL} / \mathrm{min}) ; \mathrm{CON}=$ daily average milk consumption $(\mathrm{L} / \mathrm{d})$; URV = daily average unrewarded visits to the feeder (no.). Parallel interpretation = the signal had to be positive for DS or CON or both for the test to be considered positive. Series interpretation = the signal had to be positive for DS and CON for the test to be considered positive.

the Sp and NPV were only $49.5 \%$ (95\% CI: 41.1, 57.6) and $38.9 \%$ (95\% CI: 29.1, 47.4), respectively. When considering 2 parameters in combination, a signal on DS and CON interpreted in parallel had the highest Se to detect a sick calf with an Se of $70.9 \%$ (95\% CI: $62.1,78.5)$ and a PPV of $65.3 \%$ (95\% CI: 53.5, 75.4). However, the Sp and NPV were only $32.9 \%$ (95\% CI: $26.7,40.3)$ and $38.7 \%$ (95\% CI: 28.0, 50.6), respectively. Parallel interpretation of the 3 feeding behavior parameters in combination resulted in an Se of $74.9 \%(95 \%$ CI: 65.5, 82.6), an Sp of 27.1\% (95\% CI: 21.7, 33.2), a PPV of $64.6 \%$ (95\% CI: 52.5, 75.1), and an NPV of $37.4 \%$ (95\% CI: 27.1, 48.9). The remaining diagnostic test characteristic results are reported in Table 5.

\section{DISCUSSION}

This is the first study to investigate the application of SPC techniques to daily average feeding behaviors in preweaned dairy calves to detect disease. As part of our investigation, we considered not only the diagnostic test characteristics of using CUSUM control charts to detect disease but also the timeliness of a signal relative to disease detection by trained calf personnel.

\section{Signal Timing Relative to Day of Treatment}

The results of our analysis showed that single or 2-way combinations of signals that contain DS provide the most timely signal relative to a treatment for clini- cal diagnosis, with positive signals occurring up to 3.1 d before disease detection by trained calf personnel. Very few studies have investigated the timing of control chart signaling relative to disease onset in individual animals (Quimby et al., 2001; Madsen and Kristensen, 2005; Lukas et al., 2009). Lukas et al. (2009) described the application of CUSUM charting to milk yield and milk conductivity to detect disease in lactating dairy cows. These authors found that these techniques could provide a signal up to $9 \mathrm{~d}$ before diagnosis of clinical disease by farm personnel, but there was also a very high false-positive rate (98\%); this makes this detection technique less useful in the field setting, as over time a high proportion of false-positive results could lead to producer abandonment.

Quimby et al. (2001) explored the application of self-starting CUSUM charts to time at the feed bunk in young steers and its association with when the calf was detected as sick by a pen rider. These authors found that a positive signal (based on a reduction in time spent at the feed bunk) could detect an animal with bovine respiratory disease up to $4 \mathrm{~d}$ before an experienced pen rider. Madsen and Kristensen (2005) also found a timing advantage when applying similar charting techniques to piglet water drinking behavior and were able to predict diarrheal onset $1 \mathrm{~d}$ before the start of clinical signs.

Although it is difficult to compare across studies because of age, species, differences in charting techniques, and differences in the data that these studies analyzed, 
our results also show a timing advantage to using CUSUM charts to detect disease compared with detection by farm personnel. However, this difference varies depending on which feeding behavior is used and in what combination. Of additional interest, although we did find a timing advantage to single and 2-way combinations of signals that contained DS, it is important to note the large range of day of signal relative to day of treatment. Many signals occurred after the calf was sick, on the day of illness detection, and more than $2 \mathrm{wk}$ posttreatment. For example, for DS and CON in parallel interpretation, only $51.7 \%$ of signals occurred during the week before or day of treatment, which one can argue might be the most useful period for calf personnel as they can then take the necessary steps of giving the calf a thorough physical exam, making a diagnosis (if appropriate), and applying an appropriate treatment. Signals that occur after the day of illness detection and treatment will be less useful to calf personnel, although we could imagine that this might still be useful to farms where staff lack the relative training and experience in detecting illness compared with calf personnel involved with this study.

\section{Diagnostic Test Characteristics}

Good performance of the control chart, defined as detecting as many problems as possible with as few false alarms as possible, is necessary for control charting to become an integrated livestock management tool (Mertens et al., 2011). To this end, it is important to report diagnostic test characteristics so the potential user has the opportunity to make an informed decision about the utility of this approach in the field. Emphasis on which test characteristics are important will depend on the use of the new index test and the goals of the user. We anticipate the use of a control chart signal as a screening test and therefore are mostly interested in maximizing test Se, but not at the expensive of acceptable Sp. International Standard ISO/FDIS 20966 (ISO, 2007) describes a minimum Se of $80 \%$ combined with a Sp of better than $99 \%$ when using automated methods (e.g., change in milk color, conductivity, cell count) to detect abnormal milk (Hogeveen et al., 2010). However, we should take caution in using similar standards in a different-age animal with a very different disease process and monitoring method. Users of the proposed method in a group of calves should be mostly interested in predictive values because these values describe the performance of the test in the field.

The results of our analysis suggest that using DS, CON, and URV in combination with parallel interpretation provides the highest Se, though there is no clear advantage to any of the single, double, or triple combination interpretation when predictive values are considered. When using DS, CON, and URV in combination with parallel interpretation, the PPV and NPV were estimated to be 64.6 and $37.4 \%$, respectively, meaning that $64.6 \%$ of calves with a positive signal will truly be diagnosed as sick at some time during their stay in the pen, whereas only $37.4 \%$ of calves that never display a positive signal will never be diagnosed as sick during their stay in the pen. Obviously, when considering both these imperfect test characteristics as well as limitations to timeliness of signals, we must conclude that applying CUSUM charting techniques to daily average computer-derived feeding behaviors will have limited utility for use in detecting disease in grouphoused preweaned dairy calves. Even if these charting techniques may be useful as an additional management tool for disease screening, this technique should not be solely relied upon, and daily examination of calves by trained calf personnel will still be necessary.

Very few investigators have described the diagnostic test characteristics of CUSUM charting techniques to detect sick livestock. Quimby et al. (2001) describes an overall Se, PPV, and accuracy of 90,91 , and $87 \%$, respectively, for the ability of a CUSUM chart to detect a sick steer. Lukas et al. (2009) found low sensitivities when using milk yield and milk electrical conductivity CUSUM control charts to detect mastitis and metabolic disease in lactating dairy cattle (range: 25.0-58.3\%); however, these sensitivities were higher than the algorithm the farm was currently using when the 2 were compared. When Cornou et al. (2008) applied CUSUM control charts to individual animal feeding rank in 3 electronic sow feeder farms, they found that the Se of the analysis to detect a sick sow ranged from 0 to $75 \%$, and this technique had a very high false-positive rate (range: 99.6-100\%). Those authors suggested that there may be utility in adding other monitoring parameters to the charting to enhance the Se of detection.

It is very difficult to compare our results with those of other studies because differences exist in species, animal age, study design, and analytic technique. When we compare our results with those of Quimby et al. (2001), perhaps the most similar study in terms of animal age, species, and technique, we find our test performance to be relatively poor. Those authors used time at the feeder as their parameter of interest, and it may be that time at the feeder is more sensitive than DS, CON, or URV to detect sick animals. Others have shown that lactating dairy cattle change the amount of time they are at the feed bunk in the days before an illness event (González et al., 2008). The hypothesis that time at the feeding station might be a useful screening tool for detecting disease requires further investigation in group-housed automatically fed preweaned calves. 


\section{Strengths and Limitations}

This is the first study to investigate the application of CUSUM charting to daily average feeding behaviors in preweaned dairy calves to detect disease. Calf management (e.g., age at introduction to pen, milk feeding programs, group sizes) and calf morbidity rates are similar to previous reports of farms using similar systems (Svensson and Jensen, 2007; Roth et al., 2009; Jorgensen et al., 2017).

Because we only included farms feeding a high plane of nutrition $(\geq 7 \mathrm{~L} / \mathrm{d})$, our results may not be generalizable to farms with restricted milk feeding programs. Another potential limitation is that we used calf personnel-reported treatment data to indicate illness rather than clinical diagnosis by a veterinarian or laboratory diagnosis. Unfortunately, having a veterinarian perform daily examinations of all calves on 10 farms would have been cost prohibitive. The potential for misclassification of calf health status could affect the results of this study in several ways. First, if calves that were truly sick were missed by calf personnel, it is possible that there are actually fewer false positives with CUSUM charting than it seems, resulting in a higher Sp and PPV for using this methodology. This would be an advantage for a screening test because the user would have even more confidence in the true meaning of a positive signal. Conversely, if calves were overtreated and the true incidence of first treatments was lower, then the Se and NPV might be underestimated in the current study. A higher NPV would be advantageous when using CUSUM charting as a screening tool because the user would be more confident in a negative result and less concerned about missing a sick calf.

One challenge lies in the attempt to apply these techniques to a biological system. Self-starting cumulative sum charting is commonly used for monitoring industrial production processes. The proper use of control charting requires that 3 assumptions are met: the data have to be stationary, independent, and follow the distribution function associated with the control chart used (Mertens et al., 2011). Livestock process data often violate the assumptions of stationary data and independence, which may explain the poor performance of control charts to detect illness in this study as well as the poor adoption of control chart techniques to monitor livestock processes. Hawkins and Olwell (1998) demonstrate that even small autocorrelation (0.25) in the data can have dramatic effects on the false-positive rate. The feeding behavior data used in this study contained significant autocorrelation from one day to the next. The average (range) correlation between days for the first $40 \mathrm{~d}$ on the group feeder for calves in this study was $0.84(0.68,0.89)$ for DS, $0.64(0.34,0.89)$ for CON, and $0.61(0.45,0.69)$ for URV. This means that for each feeding behavior, what happens today highly depends on what happened yesterday, violating the CUSUM charting assumption of independence. These high levels of autocorrelation could partially explain why control charting did not work with these data. Hawkins and Olwell (1998) suggested using a Box-Jenkins autoregressive moving average model, which could be another approach to use with this data. Feeding behavior data are also not stationary and, depending on the behavior, increase or decrease over the feeding period. We attempted to deal with this problem through the data preprocessing step of standardization. Furthermore, it may be that the magnitude of the change in daily average feeding behavior measures in individual calves from a healthy day to a sick day are simply not great enough and that other parameter monitoring such as temperature or activity may be more reliable.

Another limitation of this work is that we only compared the first signal to the first calf treatment and allowed a signal at any time during the calf's duration in the group pen to contribute toward our diagnostic test characteristic calculation. Performance of the CUSUM charting could be improved (higher Se) if all signals during the milk feeding period were considered or if a more stringent test window was applied. In the present study, a very narrow CUSUM control limit was used, which also may have contributed to the failure of the CUSUM technique because there were too many falsepositive signals, which was a function of human choice and not a failure of the CUSUM charting techniques.

Future studies should re-evaluate the approach developed in this study when using trained veterinarians or other accepted gold standard as the reference test. Furthermore, other charting techniques or feeding behavior data types should be explored before real-time validation on the farm is performed.

\section{CONCLUSIONS}

The results of this study suggest that the application of CUSUM charting techniques to daily average feeding behaviors in group-housed preweaned dairy calves may not be a useful stand-alone test to predict or detect disease. Single and combinations of signals that included DS provided the most sensitive and timely signal; however, no single or combination of feeding behavior signals provided enough of an advantage to abandon daily observation of calves. As such, it will still be necessary to have well-trained calf personnel with good observational skills observing calves daily for clinical signs of disease. 


\section{ACKNOWLEDGMENTS}

We thank our collaborator dairy farms for their willingness to participate in this project as well as Aaron Rendahl (College of Veterinary Medicine, University of Minnesota, St. Paul) and Yiwen Sun (Department of Statistics, University of Minnesota, Minneapolis) for their help with data management and coding of the control charting. The field work in Minnesota was funded by the University of Minnesota College of Veterinary Medicine Population Systems Signature Program. The Virginia component of this study was funded through the Virginia State Dairymen's Association and Land O'Lakes Animal Milk Products (Shoreview, MN). Salary support for Whitney Knauer was provided by USDA (Washington, DC) grant no. 2012-38420-30221.

\section{REFERENCES}

Borderas, T. F., J. Rushen, M. A. G. von Keyserlingk, and A. M. B. de Passille. 2009. Automated measurement of changes in feeding behavior of milk-fed calves associated with illness. J. Dairy Sci. 92:4549-4554.

Bossuyt, P. M., J. B. Reitsma, D. E. Bruns, C. A. Gatsonis, P. P. Glasziou, L. Irwig, J. G. Lijmer, D. Moher, D. Rennie, H. C. W. de Vet, H. Y. Kressel, N. Rifai, R. M. Golub, D. G. Altman, L. Hooft, D. A. Korevaar, J. F. Cohen, and STARD Group. 2015. STARD 2015: An updated list of essential items for reporting diagnostic accuracy studies. BMJ 351:h5527.

Cornou, C. J., J. Vinther, and A. R. Kristensen. 2008. Automatic detection of oestrus and health disorders using data from electronic sow feeders. Livest. Sci. 118:262-271.

Cramer, M. C., T. L. Ollivett, and A. L. Stanton. 2016. Associations of behavior-based measurements in preweaned, group-housed dairy calves. J. Dairy Sci. 99:7434-7443.

De Paula Vieira, A., A. M. de Passille, and D. M. Weary. 2012. Effects of early social environment on behavioral responses of dairy calves to novel events. J. Dairy Sci. 95:5149-5155.

De Vries, A., and J. K. Reneau. 2010. Application of statistical process control charts to monitor changes in animal production systems. J. Anim. Sci. 88(E-Suppl.):E11-E29.

Dohoo, I., W. Martin, and H. Stryhn. 2009. Veterinary Epidemiologic Research. VER Inc., Charlottetown, Prince Edward Island, Canada.

González, L. A., B. J. Tolkamp, M. P. Coffey, A. Ferret, and I. Kyriazakis. 2008. Changes in feeding behavior as possible indicators for automatic monitoring of health disorders in dairy cows. J. Dairy Sci. 91:1017-1028.

Hawkins, D. M., and D. H. Olwell. 1998. Cumulative Sum Charts and Charting for Quality Improvement. Springer-Verlag, New York, NY.

Hogeveen, H., C. Kamphuis, W. Steeneveld, and H. Mollenhorst. 2010. Sensors and clinical mastitis - The quest for the perfect alert. Sensors (Basel) 10:7991-8009.

Huuskonen, A., and H. Khalili. 2008. Computer-controlled milk replacer feeding strategies for group-reared dairy calves. Livest. Sci. 113:302-306.
ISO. (International Organization for Standardization). 2007. Automatic milking installations-Requirements for testing. ISO 20966:2007(en). Accessed Jun. 29, 2018. https://www.iso.org/obp/ ui/\#iso:std:iso:20966:en.

Jensen, M. B., L. Munksgaard, L. Mogensen, and C. C. Krohn. 1999. Effects of housing in different social environments on open field and social responses of female dairy calves. Acta. Agric. Scand. 49:113-120.

Jorgensen, M. W., A. Adams-Progar, A. M. de Passille, J. Rushen, S. M. Godden, H. Chester-Jones, and M. I. Endres. 2017. Factors associated with dairy calf health in automated feeding systems in the Upper Midwest United States. J. Dairy Sci. 100:5675-5686.

Knauer, W. A., S. M. Godden, A. Dietrich, and R. E. James. 2017. The association between daily average feeding behaviors and morbidity in automatically fed group-housed preweaned dairy calves. J. Dairy Sci. 100:5642-5652.

Kung, L., S. Demarco, L. N. Siebenson, E. Joyner, G. F. W. Haenlein, and R. M. Morris. 1997. An evaluation of two management systems for rearing calves fed milk replacer. J. Dairy Sci. 80:2529-2533.

Losinger, W. C., and A. J. Heinrichs. 1997. Management practices associated with high mortality among preweaned dairy heifers. J. Dairy Res. 64:1-11.

Lukas, J. M., J. K. Reneau, D. Wallace, D. Hawkins, and C. MunozZanzi. 2009. A novel method of measuring daily milk production and electrical conductivity to predict disease onset. J. Dairy Sci. 92:5964-5976.

Madsen, T. N., and A. R. Kristensen. 2005. A model for monitoring the condition of young pigs by their drinking behavior. Comput. Electron. Agric. 48:138-154.

McGuirk, S. 2008. Disease management of dairy calves and heifer. Vet. Clin. North America Food Anim. Pract. 24:139-153.

Mertens, K., E. Decuypere, J. De Baerdemaeker, and B. De Ketelaere. 2011. Statistical control charts as a support tool for the management of livestock production. J. Agric. Sci. 149:369-384.

Quimby, W. F., B. F. Sowell, J. G. P. Bowman, M. E. Branine, M. E. Hubbert, and H. W. Sherwood. 2001. Application of feeding behaviour to predict morbidity of newly received calves in a commercial feedlot. Can. J. Anim. Sci. 81:315-320.

Roth, B. A., E. Hillman, M. Stauffacher, and N. M. Keil. 2008. Improved weaning reduces cross-sucking and may improve weight gain in dairy calves. Appl. Anim. Behav. Sci. 111:251-261.

Roth, B. A., N. M. Keil, L. Gygax, and E. Hillman. 2009. Influence of weaning method on health status and rumen development in dairy calves. J. Dairy Sci. 92:645-656.

Steenkamer, N. 1982. Alternative housing systems for veal calves, their effect on welfare and performance and their economic feasibility. Pages 226-234 in Welfare and Husbandry of Calves: Current Topics in Veterinary Medicine and Animal Science. J. P. Signoret, ed. Martinus Nijhoff, The Hague, the Netherlands.

Svensson, C., and M. B. Jensen. 2007. Short communication: Identification of diseased calves by use of data from automatic milk feeders. J. Dairy Sci. 90:994-997.

Svensson, C., K. Lundborg, U. Emanuelson, and S. O. Olsson. 2003. Morbidity in Swedish dairy calves from birth to 90 days of age and individual calf-level risk factors for infectious diseases. Prev. Vet. Med. 58:179-197.

USDA-NAHMS. 2016. Dairy 2014. Dairy cattle management practices in the United States, 2014. Accessed Oct. 26, 2016. https://www .aphis.usda.gov/animal_health/nahms/dairy/downloads/dairy14/ Dairy14_dr_PartI.pdf. 